\title{
Modulation of CYP19 expression by cabbage juices and their active components: indole-3-carbinol and 3,3'-diindolylmethene in human breast epithelial cell lines
}

\author{
Barbara E. Licznerska $\cdot$ Hanna Szaefer • \\ Marek Murias • Agnieszka Bartoszek • \\ Wanda Baer-Dubowska
}

Received: 14 October 2011/Accepted: 10 October 2012/Published online: 23 October 2012

(C) The Author(s) 2012. This article is published with open access at Springerlink.com

\begin{abstract}
Purpose The aim of this study was to evaluate the effect of white cabbage and sauerkraut juices of different origin and indole-3-carbinol (I3C) and diindolylmethane (DIM) on expression of CYP19 gene encoding aromatase, the key enzyme of estrogen synthesis.

Methods Human breast cell lines (MCF7, MDA-MB-231 and MCF10A) were examined to compare the action of cabbage juices versus their active components (I3C, DIM). Real-time PCR and Western blot were used in order to analyse CYP19 mRNA and protein, respectively.

Results Remarkable differences in the effect on CYP19 transcript and protein level were found between the cabbage juices (in $2.5-25 \mathrm{~mL} / \mathrm{L}$ concentrations) and indoles (in 2.5-50 $\mu \mathrm{M}$ doses) in the three cell lines. While cabbage juices at the lower doses diminished the aromatase expression in nontumorigenic/immortalized MCF10A breast cells $(0.25-0.86$-fold change, $P<0.05), \mathrm{I} 3 \mathrm{C}$ and DIM were more efficient in decreasing the aromatase expression in estrogen-dependant MCF7 breast cancer cells (0.24-0.82-fold change, $P<0.05)$. Inhibition of aromatase by juice obtained from cabbage grown on industrial farm was correlated with the induction of apoptosis $(1.7-1.8$ -
\end{abstract}

B. E. Licznerska · H. Szaefer · W. Baer-Dubowska ( ()

Department of Pharmaceutical Biochemistry, Poznan University of Medical Sciences, Poznan, Poland

e-mail: baerw@ump.edu.pl

M. Murias

Department of Toxicology, Poznan University of Medical Sciences, Poznan, Poland

A. Bartoszek

Department of Food Chemistry, Technology and Biotechnology, Gdansk University of Technology, Gdansk, Poland fold change, $P<0.01$ ) in MCF10A cells. In estrogenindependent MDA-MB-231 cells, up-regulation of CYP19 expression by $\mathrm{I} 3 \mathrm{C}$ and DIM (1.5-2.0-fold change, $P<0.05)$ was observed. Similarly, in MCF7 cells juices increased aromatase expression (1.1-2.2-fold change, $P<0.05$ ).

Conclusion These results, particularly that obtained in nontumorigenic/immortalized MCF10A cells, suggest that chemopreventive activity of cabbage against breast cancer observed in epidemiological studies may be partly explained by inhibition of the aromatase expression.

Keywords CYP19 - Cabbage juices - Indole-3-carbinol . Diindolylmethane $\cdot$ Apoptosis - Breast cancer chemoprevention

\section{Introduction}

Breast cancer is the most common cancer of women and the leading cause of cancer mortality among women worldwide. Improvements in survival in the industrial world seen in recent decades have been attributed not only to early detection and treatment improvement, but also prophylaxis [1]. Estrogens play an important role in breast cancer development acting as promoters and initiators of carcinogenesis process. The latter activity is related to mutations caused by certain estrogen metabolites [2, 3]. Thus, estrogens are classified as carcinogenic in humans and one of the most important risk factor of breast cancer [4]. Aromatase, a cytochrome P450 encoded by CYP19, is the enzyme that synthesizes estrogens by converting $\mathrm{C} 19$ androgens into aromatic C18 estrogenic steroids. Several studies have shown that there is a high expression of aromatase in breast cancer tissue [5]. When compared to 
circulating estrogen, in situ produced estrogen has also been shown to play significant role in breast cancer growth [6]. Therefore, suppression of in situ estrogen formation, particularly in the breast of postmenopausal women by aromatase inhibitors (AIs), is considered as a useful way to prevent and treat breast cancer in these patients.

Many epidemiological studies have shown that a diet high in fruits and vegetables can reduce breast cancer incidence [7]. Moreover, it was demonstrated that many phytochemicals are aromatase inhibitors suppressing in situ estrogen biosynthesis $[8,9]$. Epidemiological studies have also demonstrated that consumption of Brassica vegetables is associated with a lower incidence of cancers [10]. In Central and Eastern European diet the most common Brassica genus is white cabbage and its fermented product, sauerkraut. However, in contrast to the other Cruciferae representatives, anti-carcinogenic activity of white cabbage and sauerkraut were less extensively studied. Epidemiological migrant studies have shown that consumption of these food items during adolescence was associated with a $72 \%$ reduced risk of breast cancer [11]. Like other vegetables, Brassica contain a number of phytochemicals with chemopreventive properties. However, they are unique in that they are rich sources of glucosinolates (GLS). Depending on the type and conditions of processing, GLS undergo either enzymatic hydrolysis or thermal degradation resulting in the formation of biologically active compounds including indoles (e.g., indole-3-carbinol, I3C and $3,3^{\prime}$-diindolylmethane, DIM). The effect of fermentation on GLS degradation products has been poorly recognized [12, 13]. The formation of some specific products like ascorbigen (ABG) is suggested [14]. I3C and its condensation product, DIM, stimulates a number of cellular responses that are proapoptotic, anti-proliferative, and anti-estrogenic [15-17]. Besides, all the compounds mentioned above may potentially affect the estrogen biosynthesis pathways.

The aim of this study was to evaluate the effect of raw cabbage and sauerkraut juices of different origins (industrial or organic farming) and their major indole components (I3C and DIM) on aromatase expression in two breast cancer cell lines differing in estrogen receptor status (MCF7-estrogen dependant and MDA-MB-231-estrogen independent) and comparison with nontumorigenic/ immortalized breast cell line (MCF10A).

\section{Methods and materials}

\section{Materials}

Indole-3-carbinol, dithiothreitol, antibiotics solution $\left(10^{4} \mathrm{U}\right.$ penicillin, $10 \mathrm{mg}$ streptomycin, $25 \mu \mathrm{g}$ amphotericin $\mathrm{B}$ ), bovine serum albumin, dimethylsulfoxide (DMSO), fetal bovine serum, Dulbecco's Modified Eagle's Medium (DMEM), hydrocortisone, $10 \mathrm{mg} / \mathrm{ml}$ insulin, $100 \mu \mathrm{g} / \mathrm{ml}$ EGF, horse serum, 3-(4,5-dimethylthiazol-2-yl)-2,5-diphenyltetrazolium bromide (MTT), RIPA buffer, trypsin, Tris, tRNA from Escherichia coli were purchased from Sigma Chemicals Co. (St Louis, MO, USA). 3,3'-diindolylmethane was obtained from LKT Laboratories (St. Paul, MN, USA). Antibodies were supplied by Santa Cruz Biotechnology (Santa Cruz, CA, USA). Rainbow colored protein molecular weight marker was purchased from Amersham Pharmacia Biotechnology (Piscataway, NJ, USA). Protease inhibitor tablets were obtained from Roche Diagnostics GmbH (Penzberg, Germany). All other chemicals were commercial products of the highest purity available. I3C and DIM were dissolved in DMSO at a concentration of $100 \mathrm{mM}$ and stored at $-20{ }^{\circ} \mathrm{C}$.

Preparation of juices

The following juices were used in the experiments: SI, sauerkraut juice from industrial farming; RI, raw juice from industrial farming; SO, sauerkraut juice from organic farming; RO, raw juice from organic farming. Fresh white cabbage was purchased in a wholesale shop supplying the area of Gdansk (Poland) in vegetables and from organic farm "FOHAT" (certificate $\mathrm{N}^{\circ}$ 92042A). The juices' preparation and standardization was performed as previously described $[18,19]$. In fresh juice, the average content of GLS was 3.283-4.623 $\mu \mathrm{mol} / \mathrm{g}$ of dry mass and of I3C was $11.37-14.81 \mu \mathrm{M}$. In sauerkraut juice, the content of most GLS was below the level of detection and I3C was 20.53-32.10 $\mu \mathrm{M}$. Before adding to the cell culture medium, sauerkraut juices were neutralized with $\mathrm{NaOH}$ to $\mathrm{pH} \sim 7.4$ to avoid acidifying cell culture medium and sterilized by filtration through $\emptyset 22 \mu \mathrm{m}$ filters.

\section{Cell culture and treatment}

MCF7 (ECACC 86012803) and MDA-MB-231 (ECACC 92020424) cells were purchased from the European Collection of Cell Cultures (Salisbury, Wiltshire, UK). MCF10A (ATTC CRL-10317) cell line was a gift of Dr Blazej Rubis (Dept Clinical Chem Molecular Diagnostics, PUMS). MCF7 and MDA-MB-231 cells were cultured in DMEM supplemented with $10 \%$ fetal bovine serum and $1 \%$ antibiotics solution. To assess the effects of tested compounds, the cells were grown in the presence of $5 \%$ fetal bovine serum. MCF10A cells were cultured in DMEM supplemented with $0.1 \%$ insulin solution, $0.02 \%$ EGF solution, $0.05 \%$ hydrocortisone solution, $5 \%$ horse serum, and $1 \%$ antibiotics solution. All cell lines were routinely maintained in $\mathrm{T} 75$ flasks in a $37{ }^{\circ} \mathrm{C}$ humidified environment of $5 \% \mathrm{CO}_{2} / 95 \%$ air and were passed twice a 
week using $0.05 \%$ trypsin/0.02 \% EDTA. Experiments were conducted at a cell density of $70 \%$ confluency. After $24 \mathrm{~h}$ preincubation, the cells were treated with raw cabbage, sauerkraut juices, I3C or DIM at the doses selected based on cytotoxicity assay: $2.5-25 \mathrm{~mL} / \mathrm{L}$ of juices; $10-50 \mu \mathrm{M}$ of I3C, and 2.5-10 $\mu \mathrm{M}$ of DIM. The incubation was continued for subsequent $72 \mathrm{~h}$. Control cells were treated with vehicle (DMSO or water). The concentration of DMSO did not exceed $0.1 \%$.

\section{Cytotoxicity assay}

Cytotoxicity was measured using the MTT assay according to standard protocols. The cells were seeded in a 96-well culture plate. After $24 \mathrm{~h}$ preincubation in the culture medium, $2.5-100 \mathrm{~mL} / \mathrm{L}$ of cabbage juices or $5-100 \mu \mathrm{M}$ of indoles (I3C and DIM) were added and the cells were incubated for $72 \mathrm{~h}$. Subsequently, the cells were washed with PBS buffer, and fresh medium containing MTT salt $(0.5 \mathrm{mg} / \mathrm{mL})$ was added to the wells. After $4 \mathrm{~h}$ incubation, the formazan crystals were dissolved in acidic isopropanol and the absorbance was measured at 570 and $690 \mathrm{~nm}$.

Apoptosis detection

The cell apoptosis ELISA detection kit (Roche, Palo Alto, CA, USA) was used to detect apoptosis in breast cancer cells treated for $72 \mathrm{~h}$ with cabbage juices, I3C or DIM according to manufacturer's protocol. Briefly, $10^{4}$ of each cell line cells were used in a 48-well culture plate, and the cytoplasmic histone/DNA fragments were extracted and bound to immobilized anti-histone antibody. Subsequently, the peroxidase-conjugated anti-DNA antibody was used for the detection of immobilized histone/DNA fragments. After addition of peroxidase substrate, the absorbance was measured at 405 and $490 \mathrm{~nm}$.

Measurement of aromatase mRNA transcript (real-time PCR)

Total RNA was isolated using the GenElute Mammalian Total RNA Miniprep Kit (Sigma, St Louis, MO, USA) according to manufacturer's recommendations and subjected to reverse transcription using the RevertAid First Strand cDNA Synthesis Kit (Fermantas, St. Leon-Rot, Germany), followed by quantitative real-time PCR. For real-time analyses, the Maxima SYBR Green/ROX qPCR Master Mix (Fermentas) and BioRad Chromo4 were used. The protocol started with a 5 min enzyme activation at $95{ }^{\circ} \mathrm{C}$, followed by 40 cycles of $95{ }^{\circ} \mathrm{C}$ for $15 \mathrm{~s} ; 56{ }^{\circ} \mathrm{C}$ for $20 \mathrm{~s} ; 72{ }^{\circ} \mathrm{C}$ for $40 \mathrm{~s}$ and the final elongation at $72{ }^{\circ} \mathrm{C}$ for $5 \mathrm{~min}$. The melting curve analysis was used for product size verification. Experiments were normalized for the expression of $T B P$ and $P B G D$. The
Pfaffl relative method was used for fold change quantification. Following primers were used: forward and reverseCYP19 (MCF7 and MCF10A: 5'CAAGAAGAGCGTGT TAGAGG3' and 5'CTGGACAGGTTGGAGGAG3'; MDA-

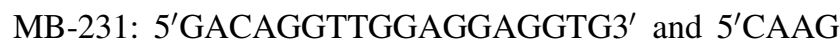
AAGAGCGTGTTAGAGG3 $\left.{ }^{\prime}\right) ; \quad P B G D \quad\left(5^{\prime}\right.$ 'TCAGATAG CATACAAGAGACC $3^{\prime}$ and $5^{\prime}$ TGGAATGTTACGAGCA GTG3'); TBP (5'GGCACCACTCCACTGTATC $3^{\prime}$ and 5'GGGATTATATTCGGCGTTTCG3').

Measurement of aromatase protein level (Western blot)

The adherent and floating cells were harvested and lysed in RIPA buffer supplemented with proteinase inhibitors and incubated on ice for $60 \mathrm{~min}$. Cell lysate was centrifuged at $14,000 \mathrm{rpm}$ for $15 \mathrm{~min}$, and the supernatant was recovered. Equal amounts of protein $(100 \mu \mathrm{g})$ were subjected to $10 \%$ SDS-PAGE slab gels and transferred to nitrocellulose membranes (Immobilon-P; Millipore, Bedford, MA, USA). After blocking with $10 \%$ skimmed milk, the proteins were probed with polyclonal goat CYP19 and polyclonal rabbit $\beta$-actin antibodies (Santa Cruz, CA, USA). As the secondary antibodies, the alkaline phosphatase-labeled antigoat IgG or anti-rabbit IgG were used. Protein contents were measured using albumin as a standard and the $\beta$-actin protein as an internal control. The amount of immunoreactive product in each lane was determined by densitometric scanning using a BioRad GS710 Image Densitometer (BioRad Laboratories, Hercules, CA, USA). The values were calculated as relative absorbance units (RQ) per mg protein.

Statistical analysis

Statistical analysis was performed by one-way ANOVA. The statistical significance between the experimental groups and their respective controls was assessed by Tukey's post hoc test at $P<0.05$.

\section{Results}

Effect of cabbage juices and indoles on cytotoxicity

Figure 1 presents the data on cytotoxicity. Cabbage and sauerkraut juices at the concentrations above $25 \mathrm{~mL} / \mathrm{L}$ significantly reduced the cytotoxicity, particularly MDAMB-231 cells $\left(\mathrm{IC}_{50}\right.$ : 7.2-35.1). DIM was more toxic than I3C ( $\mathrm{IC}_{50}$ : 17.8-51.5 and $\mathrm{IC}_{50}: 51.5-74.6$, respectively) and similarly as in case of cabbage juices the MDA-MB231 cells were the most sensitive $\left(\mathrm{IC}_{50}: 17.8-51.5\right)$. In subsequent experiments, the nontoxic concentrations (cytotoxicity above $70 \%$ based on MTT assay) were used. 
Effect of cabbage juices and indoles on the expression of CYP19

The expression of $C Y P 19$ was determined at the transcript and protein levels, and no significant differences in the constitutive expression were found between the cell lines tested. However, treatment with cabbage juices or indoles changed CYP19 transcript and protein levels in a dose and cell line-dependent manner.

In MCF7 cells, both raw cabbage (except $10 \mathrm{~mL} / \mathrm{L}$ of RI) and sauerkraut juices increased the CYP19 transcript (1.2-2.0-fold change, Fig. 2a) in comparison with control cells (treated with vehicle only). The higher increase was observed in the case of sauerkraut juice. However, treatment with raw cabbage and sauerkraut juices had no effect on protein level (except $10 \mathrm{~mL} / \mathrm{L}$ of SO, Fig. 2b). In contrast to cabbage juices, DIM (doses 5 and $10 \mu \mathrm{M}$ ) significantly reduced both CYP19 transcript (0.24-0.54-fold change, Fig. 2c) and protein levels (0.79-0.82-fold change, Fig. 2d). Also treatment with $\mathrm{I} 3 \mathrm{C}$ resulted in evident decrease in mRNA level (0.25-0.56-fold change, doses 30 and $50 \mu \mathrm{M}$, Fig. 2c) and protein level (0.82-fold change, dose $50 \mu \mathrm{M}$, Fig. 2d).

In estrogen-independent MDA-MB-231 cells, cabbage juices depending on their origin and processing they either reduced, had no effect or increased CYP19 transcript (Fig. 3a) and, similarly as in ER-positive MCF7 cells, cabbage juices did not change the aromatase protein level (Fig. 3b). DIM at the concentration of $5 \mu \mathrm{M}$ increased CYP19 transcript (2.0-fold change, Fig. 3c) in comparison with the control cells (treated with DMSO), while both indoles enhanced aromatase protein level (1.5-1.6-fold change, Fig. 3d).

The most interesting changes as result of cabbage juices treatment were observed in MCF10A cells. Most raw cabbage and sauerkraut juices significantly reduced the expression of $C Y P 19$ at the level of both the transcript and the protein (0.25-0.82-fold change, Fig. 4a, b).

Surprisingly, RI in a dose of $25 \mathrm{~mL} / \mathrm{L}$ increased mRNA (Fig. 4a), but decreased its protein level (Fig. 4b). In this
Fig. 1 The effect of cabbage juices and indoles on the cytotoxicity of MCF7, MDAMB-231, and MCF10A cells. Mean values from three separate experiments run in triplicate \pm SEM are shown
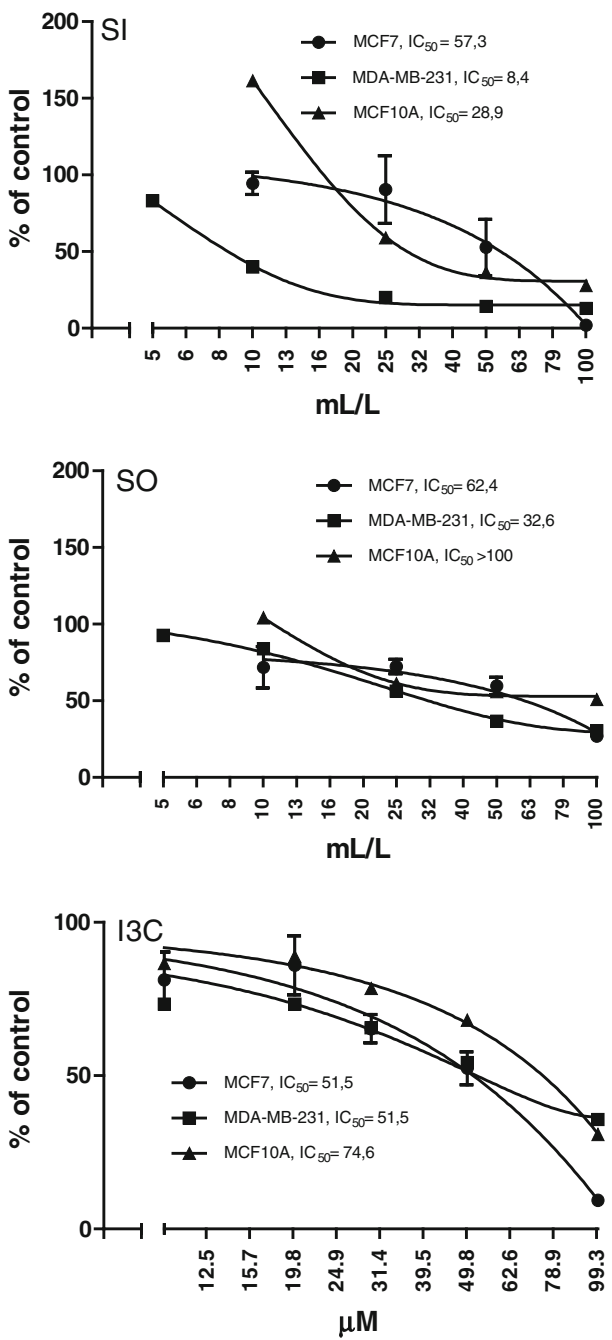
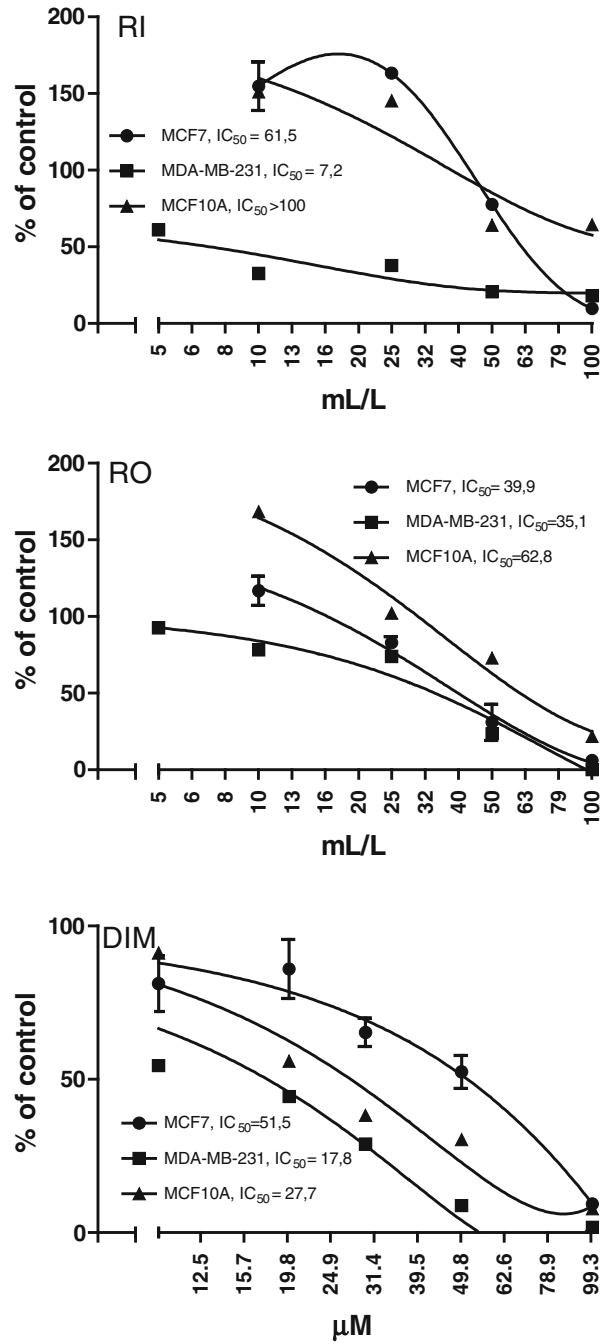
Fig. 2 The effect of $72 \mathrm{~h}$ incubation with cabbage juices $(\mathbf{a}, \mathbf{b})$ and indoles $(\mathbf{c}, \mathbf{d})$ on the level of the CYP19 transcript $(\mathbf{a}, \mathbf{c})$ and protein $(\mathbf{b}, \mathbf{d})$ in MCF7 cells. The values were calculated as a relative change in transcript or protein level in comparison with control cells (expression equals 1). The mean values \pm SEM from three independent experiments run in duplicate (protein) or triplicate (mRNA) are presented. The single asterisk above the bar denotes significant difference of mean values from the control group $(P<0.05)$; double asterisk indicates trend toward significant difference of mean values from the control group $(P<0.054)$ (a)

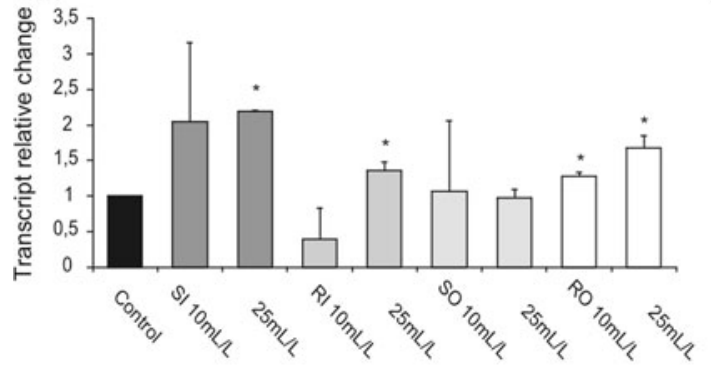

(b)
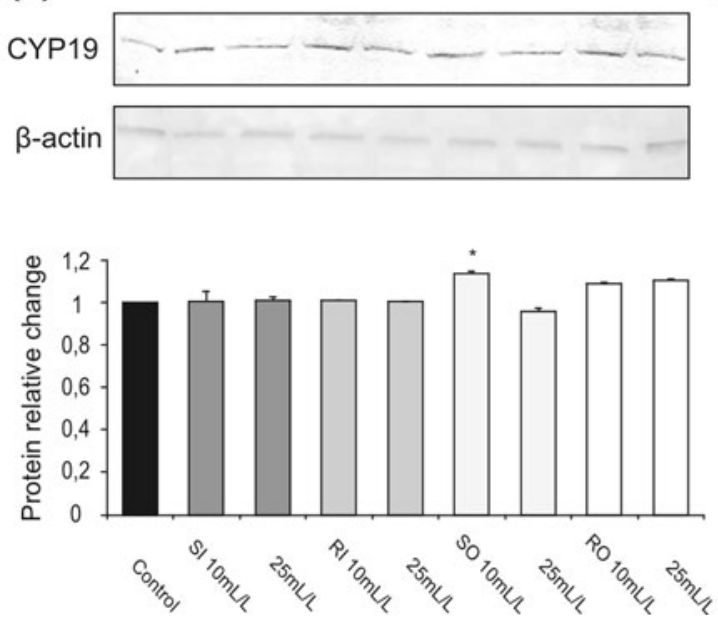

(c)

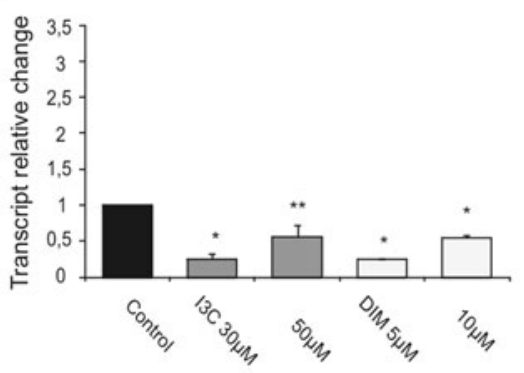

(d)
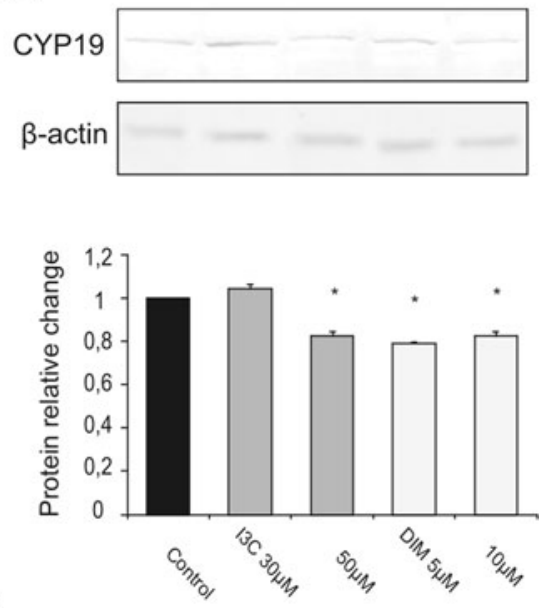

cell line, I3C $(10 \mu \mathrm{M})$ decreased CYP19 transcript $(0.68$ fold change, Fig. $4 \mathrm{c})$, while DIM $(10 \mu \mathrm{M})$ increased it (1.3fold change, Fig. 4c), but they both did not affect its protein level (Fig. 4d).

Interestingly, in general, the decrease in aromatase expression was more exerted by lower doses of tested juices and indoles (Figs. 2c, d; 3a; 4a).

Effect of cabbage juices and indoles on apoptosis induction

The results of ELISA test detecting histone/DNA fragments are shown in Fig. 5. Juices obtained from cabbage grown on industrial farm-induced apoptosis in MCF10A cells, but only in lower doses (1.7-1.8-fold change, Fig. 5c), while in breast cancer cells particularly MCF7 the anti-apoptotic effect was observed as result of juices' treatment (0.36-0.91-fold change) except SO in $25 \mathrm{~mL} / \mathrm{L}$ and RO in $10 \mathrm{~mL} / \mathrm{L}$ (Fig. 5a). In lower concentrations, I3C and DIM-induced apoptosis in ER-negative MDA-MB-231 (1.9-2.2-fold change, Fig. 5e), but only $\mathrm{I} 3 \mathrm{C}$ in a dose $10 \mu \mathrm{M}$ shown such activity in nontumorigenic MCF10A cells (2.2-fold change, Fig. 5f). In ER-positive cancer cells, treatment with these compounds (except $50 \mu \mathrm{M}$ I3C) resulted in reduced level of histone/DNA fragments in comparison with control untreated cells $(0.45-0.80$-fold change, Fig. 5d). Similarly, in MCF10A cells, only DIM in dose $10 \mu \mathrm{M}$ exerted anti-apoptotic effect (0.73-fold change, Fig. 5f). Moreover, as in expression analyses, the proapoptotic effect of tested juices and indoles was usually more evident in lower doses.

\section{Discussion}

Estrogens are a key regulator of the proliferation and differentiation of breast cancer cells. In addition to the estrogen supply from the ovary, estrogens are produced locally from androgen by aromatase. Although AIs are important drugs in hormonal therapy for breast cancer in postmenopausal women, there are concerns about the side effects associated with the estrogen deprivation achieved with AIs [20]. Phytochemicals are considered attractive alternative to synthetic drugs, and many have been documented to be aromatase inhibitors in vitro and/or in vivo [9]. They represent different classes of natural products, but except red wine extracts [8], none of the studies on the potential aromatase inhibitors included the natural food matrix.

In our study, we evaluated the effect of cabbage and sauerkraut juices as well as their major ingredients-indoles (I3C and DIM) on aromatase expression in three 

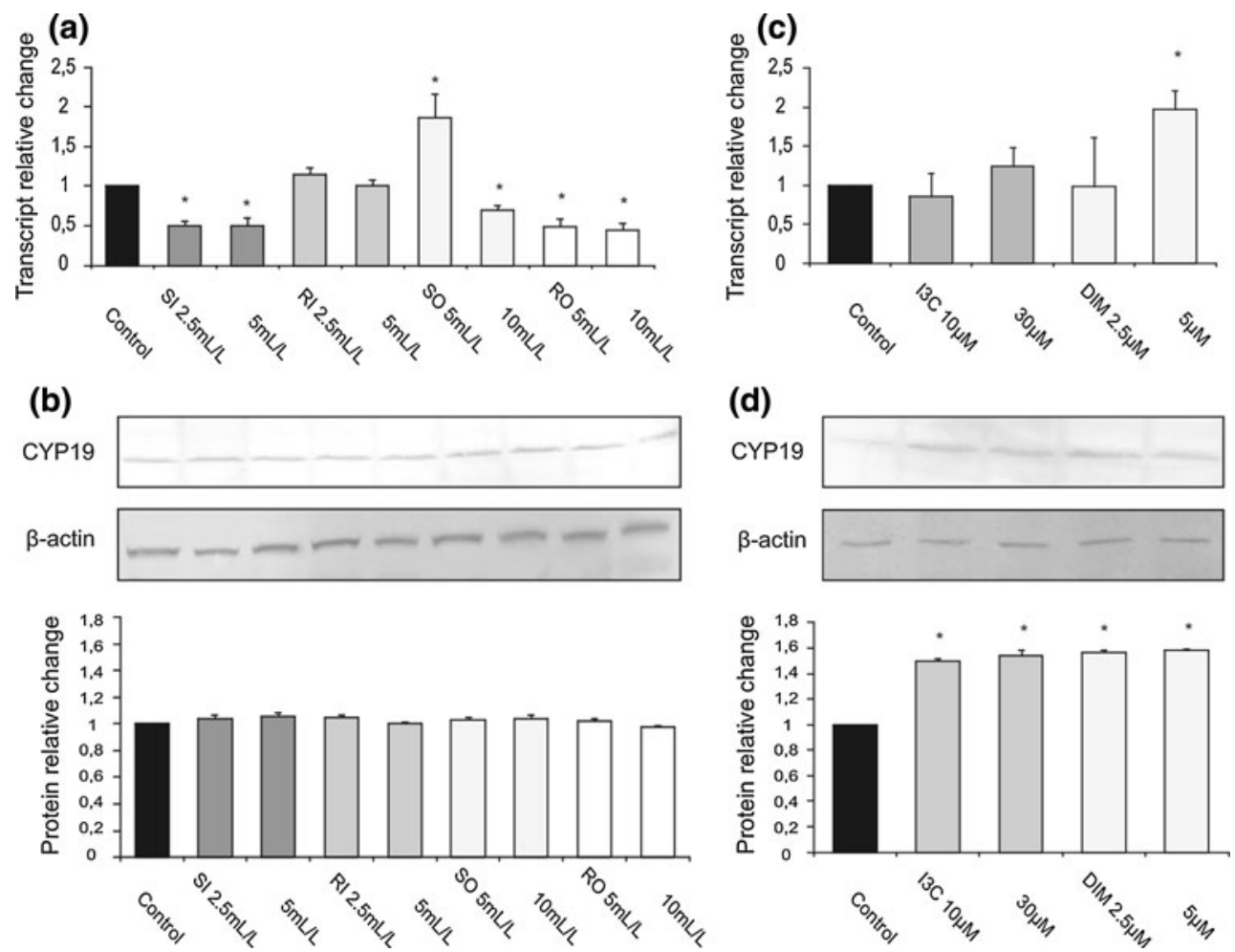

Fig. 3 The effect of $72 \mathrm{~h}$ incubation with cabbage juices $(\mathbf{a}, \mathbf{b})$ and indoles (c, d) on the level of the CYP19 transcript (a, c) and protein $(\mathbf{b}, \mathbf{d})$ in MDA-MB-231 cells. The values were calculated as a relative change in transcript or protein level in comparison with control cells

breast cell lines. MCF7 cell line is the most widely studied breast carcinoma cell line because of its steroid receptor status and estrogen sensitivity [21]. In contrast to MCF7 cells, MDA-MB-231 cells are ER-negative and have aggressive invasion capacity [22]. The parental MCF10A cell line was derived from spontaneously immortalized breast epithelial cells [22] and is frequently used as a normal control in breast cancer studies [23].

Our real-time PCR analysis revealed the expression of CYP19 in all cell lines tested, but despite the differences in their characteristics the levels of CYP19 transcript did not differ substantially. While the presence of aromatase transcripts and protein in MCF7 cells was described by several authors [21, 24, 25], the data on constitutive expression of CYP19 in this cell line as well as in MCF10A are somehow contradictory. In this regard, Fu et al. [22] did not find the presence of CYP19 mRNA in MCF10A series of cell lines or MCF7 cells. However, they found the trichostatin A (histone deacetylase inhibitor) inducible effect on CYP19 expression in all of the cells examined.

In our study, the presence of CYP19 transcript was accompanied by detectable level of protein as measured by Western blot further supporting the presence of aromatase in all tested cell lines. Remarkable differences in the effect on the tested cell lines were found between the cabbage (expression equals 1). The mean values \pm SEM from three independent experiments run in duplicate (protein) or triplicate (mRNA) are presented. The asterisk above the bar denotes significant difference of mean values from the control group $(P<0.05)$

juices and pure indoles. Based on MTT assay, the doses of cabbage juices and indoles applied were consistently $>70 \%$ in all cell lines. However, in case of cabbage juices, differences in the cytotoxic effects between the cell lines were observed with MDA-MB-231 being the most sensitive and MCF10A the least sensitive. No such difference was found in case of indoles.

Moreover, the sauerkraut and some raw cabbage juices mostly affected the aromatase expression in nontumorigenic immortalized MCF10A breast cells, while the indoles, I3C and DIM were more efficient in decreasing the aromatase expression in estrogen-dependant MCF7 breast cancer cells. Among the juices, sauerkraut juice obtained from cabbage grown on organic farm was the most potent inhibitor of CYP19 expression both on mRNA and protein level in MCF10A cells. Our previous study showed that sauerkraut juice was also more efficient than raw cabbage juice in induction of phase II enzymes in vivo in rats [19]. The sauerkraut is the product of lactic acid fermentation of shredded and salted white cabbage. During shredding, glucobrassicin, the most commonly studied GLS, is transformed into $\mathrm{I} 3 \mathrm{C}$ by the action of myrosinase. During fermentation, as the $\mathrm{pH}$ decreases, this $\mathrm{I} 3 \mathrm{C}$ reacts nonenzymatically with L-ascorbic acid to yield ABG, which is thought to be the dominant end product of indole GLS 
Fig. 4 The effect of $72 \mathrm{~h}$ incubation with cabbage juices $(\mathbf{a}, \mathbf{b})$ and indoles $(\mathbf{c}, \mathbf{d})$ on the level of the CYP19 transcript (a c) and protein $(\mathbf{b}, \mathbf{d})$ in MCF10A cells. The values were calculated as a relative change in transcript or protein level in comparison with control cells (expression equals 1). The mean values \pm SEM from three independent experiments run in duplicate (protein) or triplicate (mRNA) are presented. The asterisk above the bar denotes significant difference of mean values from the control group $(P<0.05)$

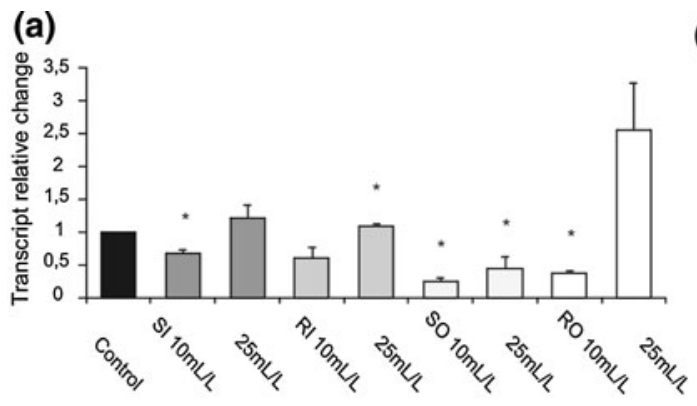

(c)

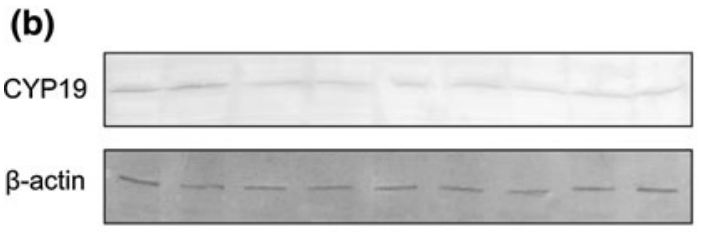

(d)

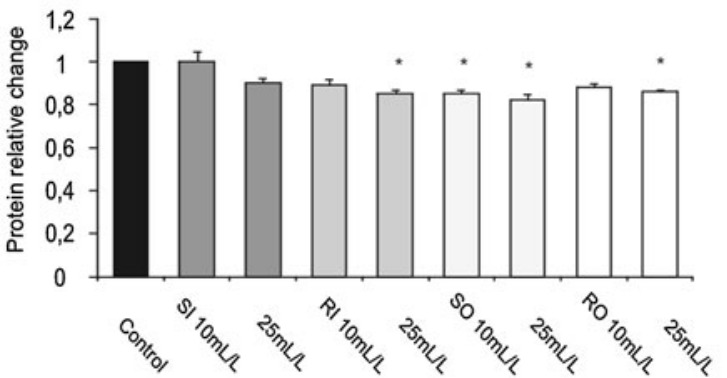

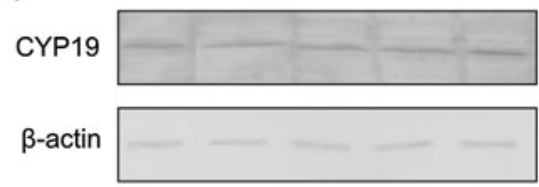
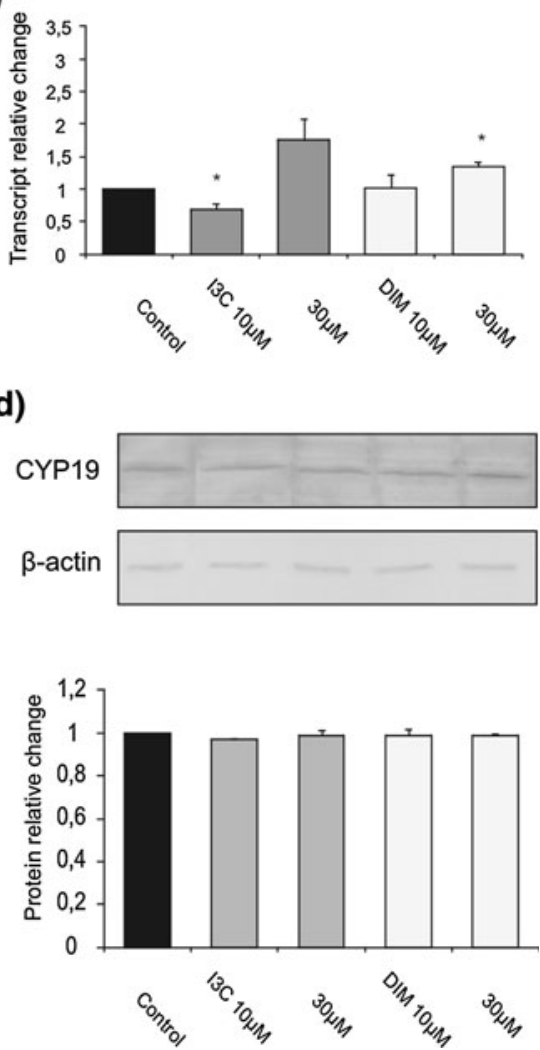

degradation in sauerkraut $[12,14]$. So far only a few and rather indirect studies on the anti-carcinogenic effects of ABG have been published, and its interaction with aryl hydrocarbon receptor (AhR) was suggested [24]. Thus, it is possible that $\mathrm{ABG}$ is also responsible for down-regulation of CYP19 expression by sauerkraut juice in MCF10A cell line.

Inhibition of aromatase by cabbage juices, particularly by $\mathrm{SI}$ in a concentration $10 \mathrm{~mL} / \mathrm{L}$, was correlated with the induction of apoptosis in MCF10A cells, which indirectly indicates that suppression of in situ estrogen formation by this cabbage juice may result in programmed cell death. Although MCF10A cells have normal mammary epithelial cell morphology, at the same time they possess a characteristic that make them a good model of breast tumor promotion [23]. This stage of carcinogenesis is characterized by clonal expansion of the initiated cells and is the most desired target of chemoprevention strategy [26]. Thus, the data provided in this study support epidemiological observations and justified application of white cabbage products in breast cancer early prophylaxis. In MDA-MB-231, ER-negative cancer cells, cabbage juices increased or decreased level of CYP19 mRNA depending on dose. This opposite effect was seen particularly in the case of sauerkraut juice obtained from cabbage grown on organic farm was observed. Up-regulation of aromatase expression was also found in MCF7 cells as result of treatment with the others cabbage juices. In both cell lines, this effect was observed on mRNA level, while protein level was not changed. While the opposite effect of different doses can be explained in part by hormetic effect [27], the discrepancy between the effect on mRNA and protein level requires further studies. It is also worth noting that cauliflower juice studied in the same breast cancer cell lines exerted cytostatic (anti-proliferative) or cytotoxic effect depending on juice concentration and cell line [28].

$\mathrm{I} 3 \mathrm{C}$ is a phytochemical that has been documented in numerous epidemiological and preclinical studies to posses mammary cancer preventive properties [29]. Once I3C reaches the acidity of the stomach, it can be converted to derivatives such as DIM. In cultured breast cancer cells, I3C has been shown to be anti-proliferative and apoptotic agent $[15,16]$. It was suggested that anti-tumorigenic effects of I3C in MCF7 human breast cancer cells may arise from its ability to reduce ER $\alpha$ expression through the binding of its metabolite, DIM to nuclear AhR [30].

Although our study did not confirm the proapoptotic activity of both compounds in MCF7 cell line, provided the first evidence that they may also down-regulate the expression of CYP19. Moreover, DIM exerted this activity in a dose of $5 \mu \mathrm{M}$, which was 6 times lower than that of I3C. It has to be stressed that in this study I3C and DIM in 
Fig. 5 The effect of cabbage juices and indoles on apoptosis in MCF7 (a, d), MDA-MB-231 $(\mathbf{b}, \mathbf{e})$, and MCF10A (c, f) cells. The mean values \pm SEM from three independent cell culture experiments run in triplicate are shown. The asterisk above the bar denotes statistically significant differences from the control group $(P<0.05)$
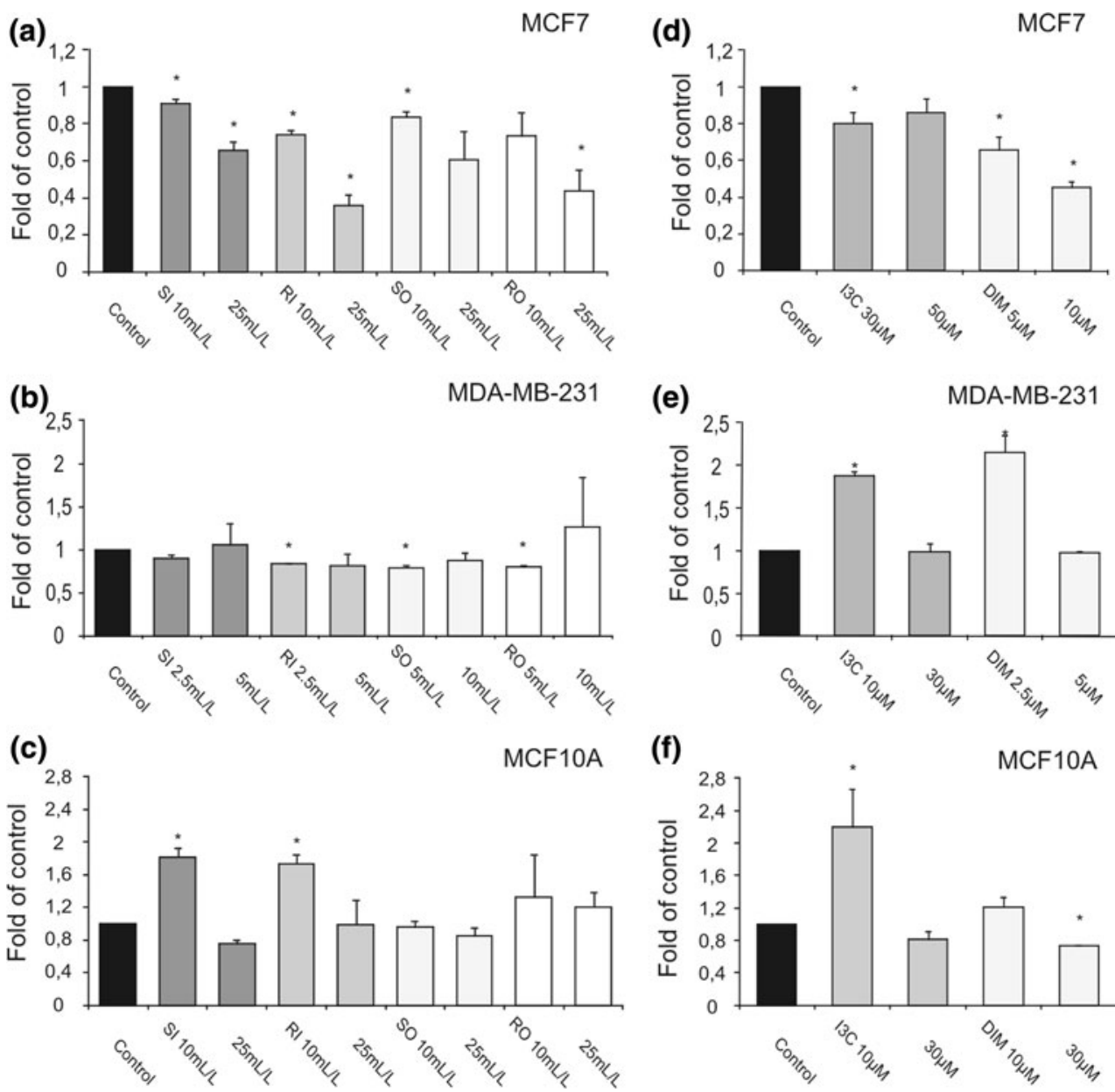

(f)

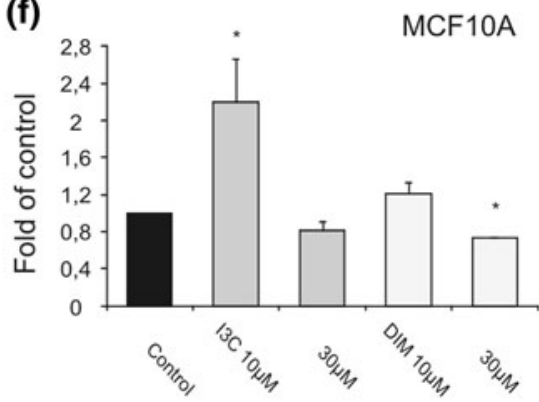

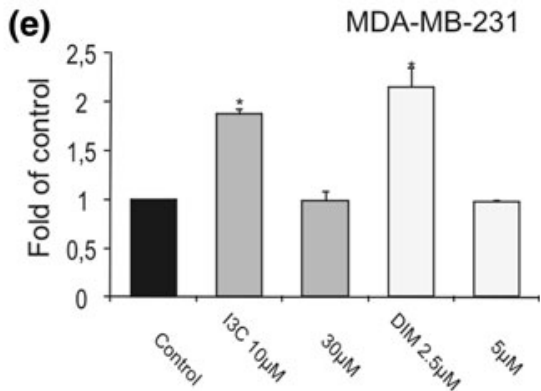

the dose $(100 \mu \mathrm{M})$ used by Wang et al. [30] showed significant cytotoxicity. The lower doses used were equivalent to those achieved in plasma [31].

Several studies on MDA-MB-231 and MCF10A cell lines have shown proapoptotic activity of both indoles [3133] and DIM [34-36]. Results of this study confirmed proapoptotic activity of I3C in a dose $10 \mu \mathrm{M}$ in ER-negative MDA-MB-231 and nontumorigenic MCF10A cells, but not in ER-positive MCF7 cell line. We have also demonstrated that DIM in a dose $5 \mu \mathrm{M}$ could favor apoptosis of MDA-MB-231, but not MCF10A and MCF7 cells, where anti-apoptotic effect was observed.

Moreover, in most cases, lower doses of juices and indoles seem to be more efficient in proapoptotic effects and in decreasing aromatase expression, and conversely less efficient in anti-apoptotic effects and in induction of aromatase expression. This observation could be partially explained by hormetic phenomena mentioned above [27].

In summary, it must be stressed that the interpretation of some results presented in this paper could be seen as somehow contradictory when changes in RNA level are not reflected in protein concentration. Thus, more studies are required in order to confirm the results of our current study.
These will include a more sensitive protein measurement technique and several cell lines differing in tumorigenicity/ invasiveness.

Nevertheless, we suggests that the results of this study indicating down-regulation of CYP19 mRNA and protein expression by cabbage juices observed in breast nontumorigenic MCF10A cell line may explain the chemopreventive activity of white cabbage and sauerkraut observed in epidemiological studies. Natural product research has continued to supply potent aromatase inhibitory lead compounds that provide interesting new avenues of investigation. White cabbage and its active components may be one of them.

Up-regulation of CYP19 expression by I3C and DIM, and together with pro-apoptotic activity observed in ERnegative MDA-MB-231 cells, suggests that inhibitors of aromatase expression may be applied only for chemoprevention and/or therapy of ER-positive breast tumors and, as shown in a recent study of Murillo et al. [37], multifunctional signal transduction inhibitors such as deguelin should be sought in order to prevent ER-negative breast cancer.

Acknowledgments This work was supported by the Ministry of Science and Higher Education of Poland, grant N405 339033. 
Conflict of interest The authors declare that they have no conflict of interest.

Open Access This article is distributed under the terms of the Creative Commons Attribution License which permits any use, distribution, and reproduction in any medium, provided the original author(s) and the source are credited.

\section{References}

1. Anderson BO, Tsu VD (2008) Breast cancer in low and middle income countries: how can guidelines best be disseminated and implemented? Breast Care 3:6-8

2. Shen L, Qiu S, Chen Y, Zhang F, van Breemen RB, Nikolic D, Bolton JN (1998) Alkylation of 2'-deoxynucleosides and DNA by the Premarin ${ }^{\circledR}$ metabolite 4-hydroxyequilenin semiquinone radical. Chem Res Toxicol 11:94-104

3. Watson CS, Gametchu B, Norfleet AM, Cambell CH, Thomas ML (1999) Rapid, nongenomic action of estrogens. LOWOC J $1: 21-28$

4. International Agency for Research on Cancer (1999) Monographs on the evolution of carcinogenic risks to humans: hormonal contraception and postmenopausal hormone therapy, vol 72 . IARC, Lyon, France

5. Lu Q, Nakmura J, Savinov A, Yue W, Weisz J, Dabbs FJ, Wolz G, Brodie A (1996) Expression of aromatase protein and messenger ribonucleic acid in tumor epithelial cells and evidence of functional significance of locally produced estrogen in human breast cancer. Endocrinology 137:3061-3068

6. Yue W, Wang JP, Hamilton CJ, Demers LM, Santen RJ (1998) In situ aromatization enhances breast tumor estradiol levels and cellular proliferation. Cancer Res 58:927-932

7. Dos Santos SI, Mangtani P, McCormack V, Bhata D, Sevak L, McMichael AJ (2002) Lifelong vegetarianism and risk of breast cancer: a population-based case-control study among South Asian migrant women living in England. Int J Cancer 99:238-244

8. Eng TE, Ye JJ, Williams D, Phung S, Moore RE, Young MK, Gruntmanis U, Braunstein G, Chen S (2003) Suppression of estrogen biosynthesis by procyanidin dimers in red wine and grape seeds. Cancer Res 63:8516-8522

9. Balunas MJ, Kinghorn AD (2010) Natural compounds with aromatase inhibitory activity: an update. Planta Med 76:1087-1093

10. Higdon JV, Delage B, Williams DE, Dashwood RH (2007) Cruciferous vegetables and human cancer risk: epidemiologic evidence and mechanistic basis. Pharmacol Res 55:224-236

11. Nelson NJ (2006) Migrant studies aid the search for factors linked to breast cancer risk. J Natl Cancer Inst 98:436-438

12. Ciska E, Pathak DR (2004) Glucosinolate derivatives in stored fermented cabbage. J Agric Food Chem 52:7938-7943

13. Martinez-Villaluenga C, Penas E, Frias J, Ciska E, Honke J, Piskula MK, Kozlowska H, Vidal-Valverde C (2009) Influence of fermentation conditions on glucosinolates, ascorbigen, and ascorbic acid content in white cabbage (Brassica oleracea var. capitata cv. Taler) cultivated in different seasons. J Food Sci 74:62-67

14. Wagner AE, Rimbach G (2009) Ascorbigen: chemistry, occurrence, and biologic properties. Clin Dermatol 27:217-224

15. Ge X, Fares FA, Yannai S (1999) Induction of apoptosis in MCF7 cells by indole-3-carbinol is independent of p53 and bax. Anticancer Res 19:3199-3203

16. Chen DZ, Qi M, Auborn KJ, Carter TH (2001) Indole-3-carbinol and diindolylmethane induce apoptosis of human cervical cells and in murine HPV-16 transgenic preneoplastic cervical epithelium. J Nutr 131:3294-3302
17. Bjeldanes LF, Kim JY, Grose KR, Bartholomew JC, Bradfield CA (1991) Aromatic hydrocarbon responsiveness-receptor agonists generated from indole-3-carbinol in vitro and in vivo: comparisons with 2,3,7,8-tetrachlorodibenzo-p-dioxin. Proc Natl Acad Sci USA 88:9543-9547

18. Kusznierewicz B, Bartoszek A, Wolska L, Drzewiecki J, Gorinstein S, Namieśnik J (2008) Partial characterization of white cabbages (Brassica oleracea var. capitata $\mathrm{f}$. alba) from different regions by glucosinolates, bioactive compounds, total antioxidant activities and proteins. LWT 41:1-9

19. Krajka-Kuźniak V, Szaefer H, Bartoszek A, Baer-Dubowska W (2010) Modulation of rat hepatic and kidney phase II enzymes by cabbage juices. Comparison with the effects of indole-3-carbinol and phenethyl isothiocyanate. Br J Nutr 23:1-11

20. Chen ZS, Ye JJ, Kijima I, Evans D (2010) The HDAC inhibitor LBH589 (panobinostat) is an inhibitory modulator of aromatase gene expression. PNAS 107:10032-11037

21. Śmuc T, Rižner TL (2009) Expression of 17 $\beta$-hydoxysteroid dehydrogenases and other estrogen-metabolizing enzymes in different cancer cell lines. Chem Biol Interact 178:228-233

22. Fu J, Weise AM, Falany JL, Falany CN, Thibodeau BJ, Miller FR, Kocarek TA, Runge-Morris M (2010) Expression of estrogenicity genes in a lineage cell culture model of human breast cancer progression. Breast Cancer Res Treat 120:35-45

23. Zientek-Targosz H, Kunnev D, Hawthorn L, Venkov M, Matsui S, Cheney RT, Ionov Y (2008) Transformation of MCF-10A cells by random mutagenesis ICRI91: a model for identifying candidate breast-tumor suppressors. Mol Cancer 7:51. doi:10.1186/1476-45987-51

24. Kravchenco LV, Avren'eva LI, Guseva GV, Posdnyakov AL, Tutel'yan VA (2001) Effect of nutritional indoles on activity of xenobiotic metabolism enzymes and T-2 toxicity in rats. Bull Exp Biol Med 131:544-547

25. Castagnetta LA, Granata OM, Bellavia V, Amodio R, Scaccianoce E, Notarbartolo M, Follari MR, Miceli MD, Carruba G (1997) Product of aromatase activity in intact LNCaP and MCF-7 human cancer cells. J Steroid Biochem Mol Biol 61:287-292

26. Baer-Dubowska W, Ignatowicz E (2006) Chemoprevention of cancer: basic mechanisms and molecular targets. In: Baer-Dubowska W, Bartoszek A, Malejka-Giganti D (eds) Carcinogenic and anticarcinogenic food components. CRC Taylor\&Francis Group, Boca Raton, pp 177-196

27. Calabrese EJ (2008) Hormesis and medicine. Br J Clin Pharmacol 66:594-617

28. Brandi G, Schiavano GF, Zaffaroni N, De Marco C, Paiardini M, Cervasi B, Magnani M (2005) Mechanisms of action and antiproliferative properties of Brassica oleracea juice in human breast cancer cell lines. Nutr Cancer 135:1503-1509

29. Shertzer HG, Senft AP (2000) The micronutrient indole-3-carbinol: implications for disease and chemoprevention. Drug Metab Drug Interact 17:159-188

30. Wang TTY, Milner MJ, Milner JA, Kim YS (2006) Estrogen receptor $\alpha$ as a target for indole-3-carbinol. J Nutr Biochem 17:659-664

31. Moiseeva EP, Almeida GM, Jones GDD, Manson M (2007) Extended treatment with physiologic concentrations of dietary phytochemicals results in altered gene expression, reduced growth, and apoptosis of cancer cells. Mol Cancer Therapy 6:3071-3079

32. Moiseeva EP, Heukers R, Manson MM (2007) EGFR and Src are involved in indole-3-carbinol-induced death and cell cycle arrest of human breast cancer cells. Carcinogenesis 2:435-445

33. Rahman KMW, Aranha O, Sarkar FH (2003) Indole-3-carbinol (I3C) induces apoptosis in tumorigenic but not in nontumorigenic breast epithelial cells. Nutr Cancer 45:101-112

34. Gong Y, Sohn H, Xue L, Firestone GL, Bjeldanes LF (2006) 3,3'diindolylmethane is a novel mitochondrial $\mathrm{H}^{+}$-ATP synthase 
inhibitor that can induce $\mathrm{p} 21^{\mathrm{Cip} 1 / \mathrm{Waf} 1}$ expression by induction of oxidative stress in human breast cancer cells. Cancer Res 66:48804887

35. Rahmann KMW, Li Y, Wang Z, Sarkar SH, Sarkar FH (2006) Gene expression profiling revealed survivin as a target of $3,3^{\prime}$ diindolylmethane-induced cell growth inhibition and apoptosis in breast cancer cells. Cancer Res 66:4952-4960

36. Rahman KMW, Ali S, Aboukameel A, Sarkar SH, Wang Z, Philip PA, Sakr WA, Raz A (2007) Inctivation of NF- $\kappa$ B by $3,3^{\prime}-$ diindolylmethane contributes to increased apoptosis induced by chemotherapeutic agent in breast cancer cells. Mol Cancer Ther 6:2757-2764

37. Murillo G, Peng XH, Torres KEO, Mehta RG (2009) Deguelin inhibits growth of breast cancer cells by modulating the expression of key members of the Wnt signalling pathway. Cancer Prev Res 2:942-950 